\title{
A 100 años de la reanudación de Gaceta Médica de México
}

\section{Martha Eugenia Rodríguez-Pérez, ${ }^{*}$ Carlos Andrés Rodríguez-Toledo y Eduardo Iván Cruz-Gaytán²}

${ }^{1}$ Facultad de Medicina, Departamento de Historia y Filosofía de la Medicina; ${ }^{2}$ Facultad de Filosofía y Letras. Universidad Nacional Autónoma de México, Ciudad de México, México

\section{Resumen}

Gaceta Médica de México, órgano oficial de la Academia Nacional de Medicina de México, empezó su tiraje el 15 de septiembre de 1864 y continúa posicionada como la publicación periódica médica de mayor antigüedad. Sin embargo, en algún momento de su historia la publicación fue suspendida temporalmente. El presente estudio analiza la interrupción que sufrió Gaceta en 1916, su reanudación en 1919 y las causas que originaron esa discontinuidad. Se habla de las consecuencias que dejó la denominada Revolución Mexicana y del entusiasmo y compromiso de la Academia y sus editores por seguir trabajando por el progreso de la medicina nacional.

PALABRAS CLAVE: Gaceta Médica de México. Academia Nacional de Medicina de México. Publicación periódica.

\begin{abstract}
Gaceta Médica de México, official journal of the National Academy of Medicine of Mexico, began its circulation on September 15, 1864, and continues to be positioned as the oldest medical periodical publication. However, its publication was temporarily interrupted. The present study analyzes the interruption suffered by Gaceta in 1916, its resumption in 1919, and the causes that originated that discontinuity. The consequences of the so-called Mexican revolution and the enthusiasm and commitment of the academy and its editors to continue working for the progress of national medicine are discussed.
\end{abstract}

KEY WORDS: Gaceta Médica de México. National Academy of Medicine of Mexico. Periodical publication.

\section{Introducción}

Desde su origen en 1864, Gaceta Médica de México fue de indiscutible importancia para la Academia Nacional de Medicina de México, puesto que ahí quedaban consignados los trabajos de turno, en su mayoría relativos a las enfermedades reinantes en México, así como las noticias médicas procedentes del extranjero y la vida de la asociación. La publicación citada interrelacionaba la Academia con otras asociaciones, permitiendo externar su posición como órgano consultivo del gobierno federal. Como revista fundamental para la ciencia y su difusión, era de vital importancia que saliera de imprenta con toda puntualidad. Sin embargo, el movimiento revolucionario que inició en México en 1910, seguido de la Guerra de Facciones, afectó a la Academia e impidió la continuidad de la publicación. El presente estudio señala la interrupción que sufrió Gaceta Médica de México en los años 1917, 1918 y primer semestre de 1919, así como su reanudación. En ese contexto de luchas internas que azotaban al país, vale la pena responder algunas preguntas: ¿cómo logró subsistir la Academia?, ¿qué dificultades enfrentó?, ¿qué acontecimientos llevaron a la discontinuidad de la Gaceta?, ¿cómo se logró su reimpresión?
Correspondencia:

*Martha Eugenia Rodríguez-Pérez

E-mail: martha.eugenia.rp@gmail.com
Fecha de recepción: 04-07-2019

Fecha de aceptación: 20-08-2019

DOI: 10.24875/GMM.19005379
Gac Med Mex. 2019;155:554-558

Disponible en PubMed www.gacetamedicademexico.com 


\section{La asociación}

Si bien es cierto que la Academia Nacional de Medicina, cuando aún se conocía como Sección de Ciencias Médicas, emergió como una asociación trascendente con el fin de socializar el conocimiento médico, para la década de los setenta del siglo XIX se posicionó como asociación epistémica, puesto que se transformó en Academia de Medicina, reconocida por el gobierno mexicano. Esa estable posición de la corporación se reafirmó en 1887, cuando se transformó en Academia Nacional de Medicina, como lo dio a conocer su titular, el doctor José María Bandera. En este último año, la Academia incrementó sus áreas de trabajo a 16: anatomía, fisiología, física y química, patologías interna y externa, operaciones, farmacología, obstetricia, medicinal legal y estadística, entre otras, que, en conjunto, fomentaban el progreso científico.

En ese camino ascendente, el reconocimiento gubernamental hacia la Academia culminó en 1912 cuando el presidente de la República, Francisco I. Madero reconoció a la corporación como una institución oficial, dado que era "ventajoso para el gobierno contar con un cuerpo docto a quien consultar en asuntos científicos de su competencia".

La Academia representó a la agrupación médica más importante del México decimonónico, que se reunía por interés propio y se comprometía a trabajar bajo ciertas normas metodológicas. Congregó a especialistas de la salud motivados por el estudio de la epidemiología nacional, la discusión de casos clínicos, la actualización de los avances de la medicina extranjera y el debate con los colegas. Todo el saber que circulaba al interior de la comunidad médica, en las sesiones de los miércoles, necesitaba resguardarse, como lo señaló el doctor Miguel Francisco Jiménez, quien ocupara la presidencia de la asociación en 1865, 1866, 1870 y 1872. Jiménez externó la importancia de que la Academia contara con un órgano de difusión: Gaceta Médica de México salió a la luz el 15 de septiembre de 1864. Ella permitiría, decía Jiménez, dejar consignados los hechos que se estaban viviendo y las aportaciones médicas para beneficio de los especialistas contemporáneos y de la posteridad. ${ }^{2}$

Conforme avanzaba el siglo XIX, la Academia crecía en cantidad y calidad. Por ejemplo, de 22 socios en 1864, ascendió a 65 en 1878. Por otra parte, al concluir el siglo XIX, su presidente saliente, el doctor Luis E. Ruiz, afirmaba que la Academia trabajaba silenciosamente, pero de un modo continuo y en la mejor forma, en una de las fases más importantes del bienestar y perfectibilidad humanas. Ruiz señalaba que la Academia laboraba con esmero por el primero de los bienes: la salud y que "cuando esta se pierde, infatigable trabaja por volverla y si esto no es dable, por aliviar los padecimientos y en todos los casos, llevar el bálsamo del consuelo al ánimo de todos los que sufren, lo que se consigue siempre". ${ }^{3}$

La Academia cerró la centuria decimonónica trabajando en pro de la medicina nacional mediante comunicaciones verbales, debates amenos, reseñas escritas, memorias, presentaciones de enfermos, instrumentos y aparatos, que en conjunto mostraban el estado de la medicina. En ese cierre de siglo, las enfermedades predominantes fueron influenza, tuberculosis pulmonar, bronquitis, neumonías y bronconeumonías. ${ }^{4}$

La Academia inició el siglo XX con gran entusiasmo bajo la titularidad de los médicos José Ramón Icaza, José Terrés, Manuel Gutiérrez Zavala, Domingo Orvañanos, Nicolás Ramírez de Arellano, Manuel Toussaint, Francisco Vázquez Gómez, Julián Villarreal, Ulises Valdés y Joaquín G. Cosío.

En 1914, al cumplirse 50 años de la fundación de la Academia Nacional de Medicina, se hacía necesaria una reflexión del camino recorrido y sus logros. Sus integrantes reconocían con júbilo el progreso de su sociedad gracias a que, en palabras del doctor Gregorio Mendizábal, socio titular de la Sección de Farmacología y Farmacia y posteriormente honorario, "ningún gobierno le había sido hostil". Ese apoyo gubernamental y los grandes maestros afiliados a la Academia desde su fundación en 1864, contribuyeron a que la práctica médica y su ciencia fueran reconocidas en el siglo XIX como las mejores de América, "y ser denominado aquel lapso con el hermoso dictado de edad de oro de la Medicina en México". ${ }^{5}$ En ese año, 1914, el doctor Mendizábal expresaba que era digno de celebrarse que la Academia continuara en activo, dadas las convulsiones políticas que se vivían, refiriéndose a la guerra civil por la que atravesaba el país desde 1910, conocida históricamente como Revolución Mexicana, lucha armada que se libró entre varios sectores demográficos y que generó inestabilidad política, económica y social a nuestra nación.

\section{Interrupción de Gaceta}

Gaceta Médica de México, órgano oficial de difusión de la Academia Nacional de Medicina, se publicó ininterrumpidamente de 1864 a 1916, no obstante que 
tuvo una periodicidad variable, la mayor parte de las veces quincenal, pero también llegó a publicarse decenal y mensualmente. Gaceta significaba un orgullo nacional porque permitía a México ser reconocido por otros centros cultos del "mundo civilizado". Se valoraba su regularidad, ya que solo así los asociados podían presentar sus trabajos en el tiempo oportuno para lograr un impacto en la medicina mundial de aquel tiempo.

Desde 1910 empezó la inestabilidad en México con la Revolución Mexicana, encaminada a derrocar al gobierno de Porfirio Díaz. La violencia empeoró en 1913 con la Decena Trágica, que terminó con los asesinatos de Madero y Pino Suárez, presidente y vicepresidente de México, respectivamente. Respecto a la vida académica del país y como efecto no solo de la Revolución Mexicana sino también de la Primera Guerra Mundial, desde 1914 empezó a escasear el papel en México y el que llegaba, se vendía a altos precios; Gaceta y muchas otras publicaciones periódicas se imprimían en papel importado. Varias revistas médicas se vieron afectadas por la situación, por ejemplo, Boletín del Instituto Patológico retrasó sus entregas, mientras que el periódico La Escuela de Medicina suprimió la edición definitivamente con el tomo 29 en 1914.

En su informe como presidente saliente de la Academia Nacional de Medicina, el doctor Joaquín G. Cosío expresó el 1 de octubre de 1915 que la corporación "ha continuado separada de la política y por ese motivo ha podido seguir su marcha habitual, sin que los rugidos de la tormenta que se han filtrado a través de estas paredes, hayan modificado en lo más mínimo la serenidad y la calma augusta de este centro científico que solo se preocupa por el bienestar del hombre..." ${ }^{\prime 6}$ Sin embargo, la situación política sí afectó a la Academia. El mayor ejemplo se dio el 10 de marzo de 1915, cuando se suspendió por primera vez en la vida de la corporación la sesión semanal, por falta de quorum, dado que el ejército de Emiliano Zapata arribó a la Ciudad de México. Otra consecuencia del ambiente bélico, tal vez la más notable, consistió en interrumpir la publicación de Gaceta Médica de México. El doctor Cosío expresó que "una circunstancia lamentable nos ha afectado durante todo el año y es la falta de publicación de $L a$ Gaceta de México órgano de nuestra Academia. Tenemos abundante material acumulado, que no se ha podido dar a luz, porque ha faltado la asignación que durante treinta y seis años se ha recibido de los diversos ministerios encargados de la educación de

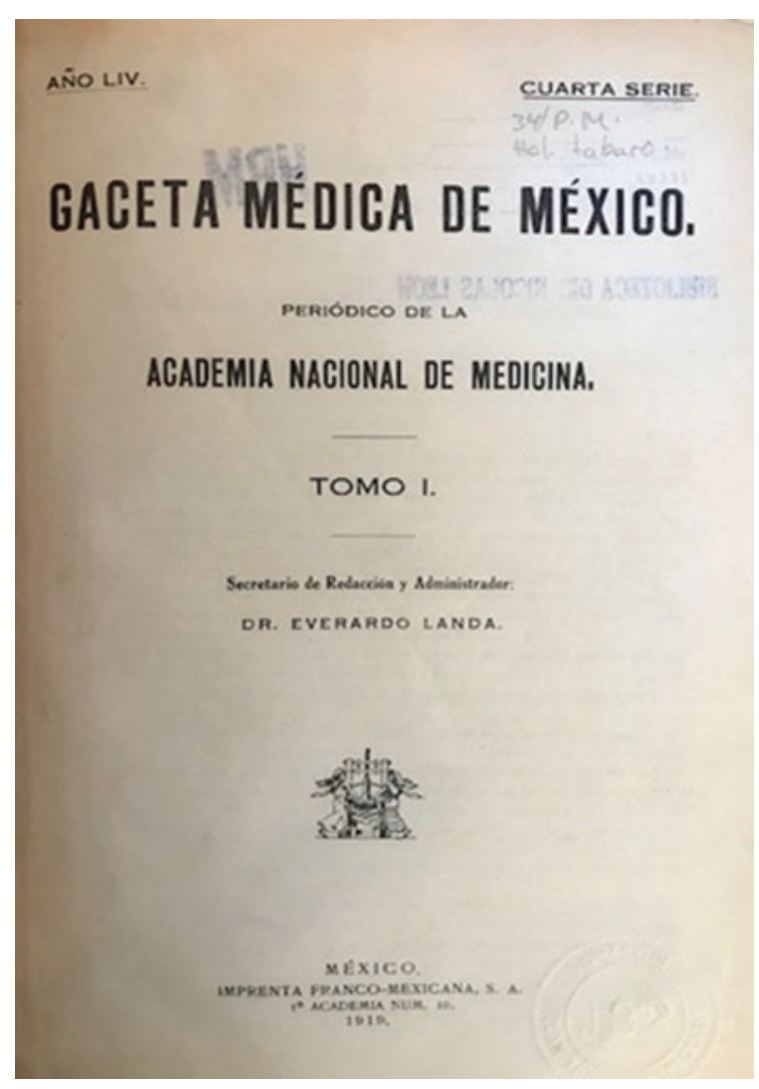

Figura 1. Portada de Gaceta Médica de México.

nuestro país". La falta de fondos aunada a la carestía extrema y los gastos de publicación obligaron al editor de Gaceta, el doctor Everardo Landa, a guardar silencio forzoso y a enfrentar el ánimo de esperar un impulso mayor a sus funciones, una vez que se renovara la situación política del país. Pese a que las dificultades políticas seguían, la Academia logró publicar Gaceta correspondiente a 1915 y, en su momento, el tomo XI de 1916, volumen con el que terminó la tercera serie.

Durante los años de carestía, de hecho a 1915 se le conoció como "el año del hambre", los gastos de pervivencia de la Academia fueron solventados directamente por los socios a través de cuotas voluntarias; incluso algunos directivos remuneraron a la Academia las gratificaciones a las que tenían derecho. Con los recursos reunidos, los miembros, al menos los titulares, pudieron continuar sus reuniones en medio de las perturbaciones de naturaleza bélica que acontecían en la Ciudad de México, puesto que todos ellos alentaban a la asociación, rendían culto al trabajo e impulsaban la medicina nacional en beneficio de su patria.

Cabe mencionar que los egresos de la corporación no solo comprendían lo correspondiente al costo del 


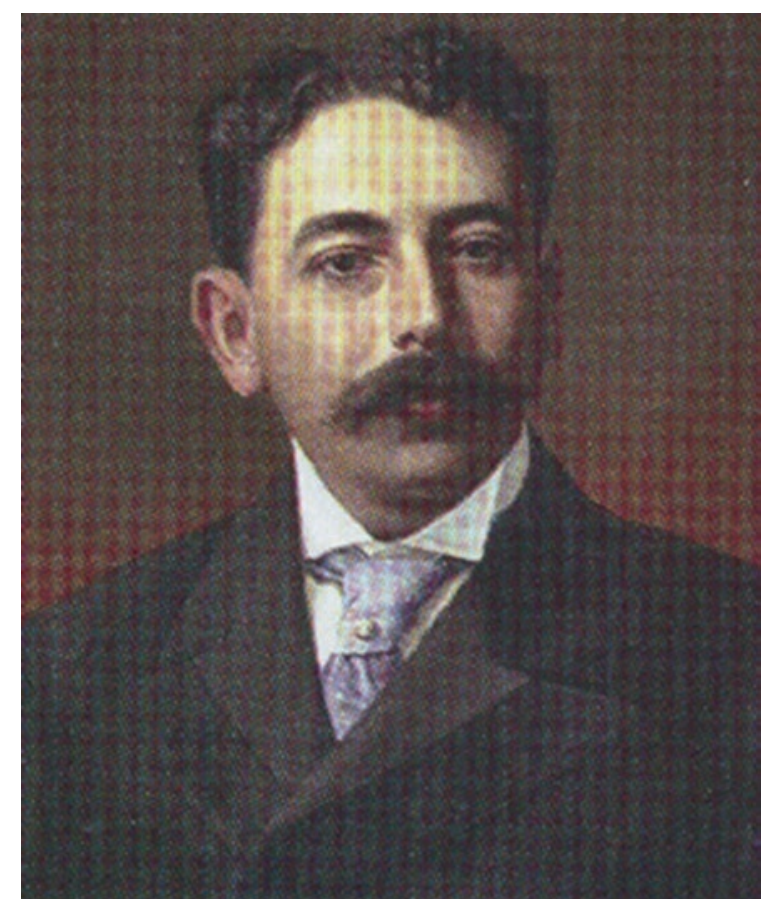

Figura 2. El doctor Emilio F. Montaño, presidente de la Academia Nacional de Medicina (1919-1920), externó el valor de Gaceta Médica de México como un medio oportuno para conocer las novedades médicas.

papel y la impresión de la gaceta, también incluían los gastos de la corporación en sí, el pago a los empleados, el tesorero, el escribiente y el mozo, así como las gratificaciones de reglamento a los académicos por los trabajos de turno. Todo ello incrementó y generó más adeudos. Por tanto, dado el crítico ambiente que vivía el país, Gaceta Médica de México fue suspendida durante 1917, 1918 y primer semestre de 1919.

\section{Reanudación de Gaceta}

El 1 de julio de 1919 se reanudó Gaceta Médica de México y se publicó el tomo 1 de la cuarta serie bajo el cuidado de sus editores, los doctores Everardo Landa y Ángel Brioso Vasconcelos, quienes reunieron en un voluminoso ejemplar los documentos relacionados con la vida de la Academia durante el periodo 1916-1919. El siguiente volumen, al cuidado solo del doctor Vasconcelos, no correspondió al tomo 2, sino al LV, debido a que se retomó la numeración general de los tomos publicados. Este último volumen, también de periodicidad irregular, correspondió a los años 1921-1925 (Figura 1).

Retomar la impresión de Gaceta significaba regular las actividades de la Academia, hecho que fue posible gracias al apoyo que le otorgaron diversos organismos:

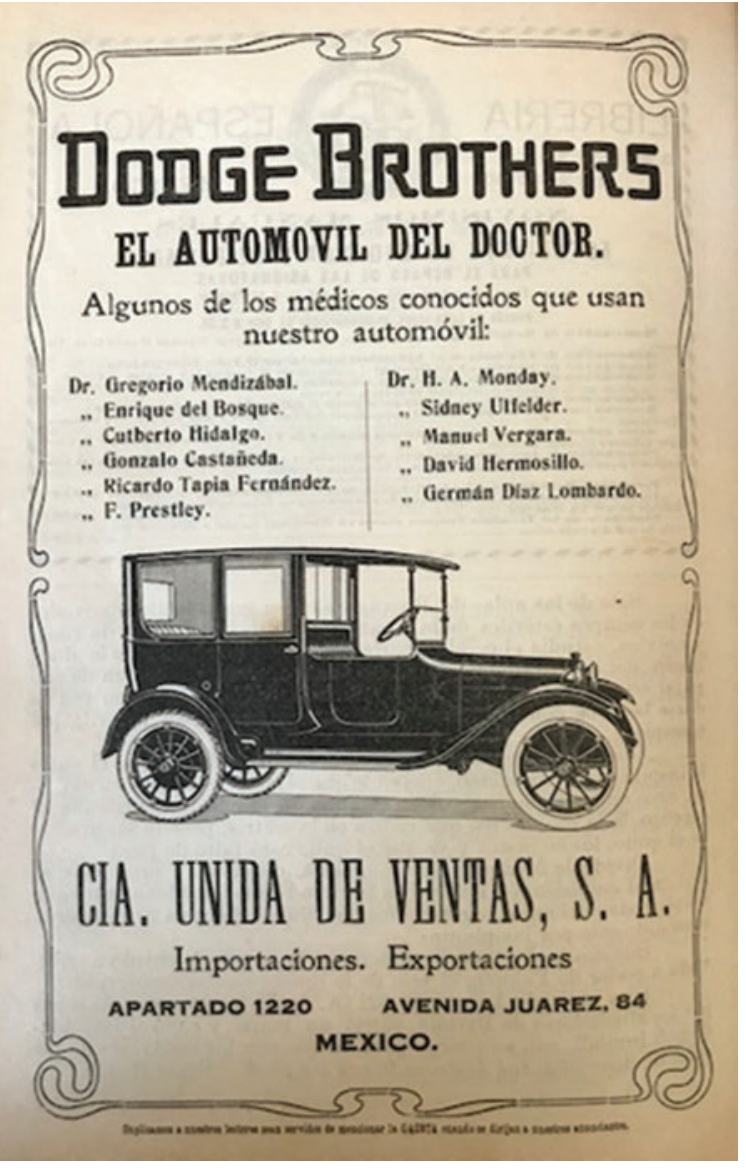

Figura 3. En 1921, Gaceta Médica de México anunció una marca de automóviles para recaudar fondos.

Consejo Superior de Salubridad, Escuela Nacional de Medicina, Instituto Bacteriológico y el diario político El Universal, así como el pago de compañías particulares que anunciaban sus productos en Gaceta; el doctor Emilio F. Montaño, presidente de la Academia en el periodo 1919-1920, decía que todavía no contaban con imitadores de Rockefeller o de Rothschild. Así, con un apoyo firme, la Academia Nacional de Medicina continuó dando servicio al público en sus oficinas y biblioteca, situadas en Brasil 33, en un horario de 7 a 9 de la noche. ${ }^{7}$ Sin un órgano de difusión, la Academia no tenía completa sus funciones, de ahí que el doctor Montaño expresara que "la vida de la Academia está vinculada con los trabajos escritos de los socios, con las discusiones que corrigen y completan estos trabajos y con la publicación de ellos en su órgano periódico: la Gaceta Médica, que da a la corporación el carácter docente."8 Asimismo, subrayaba el doctor Montaño que los progresos de la ciencia requerían nuevos procedimientos de investigación; la observación a la cabecera del enfermo necesitaba ser completada con trabajos de laboratorio 


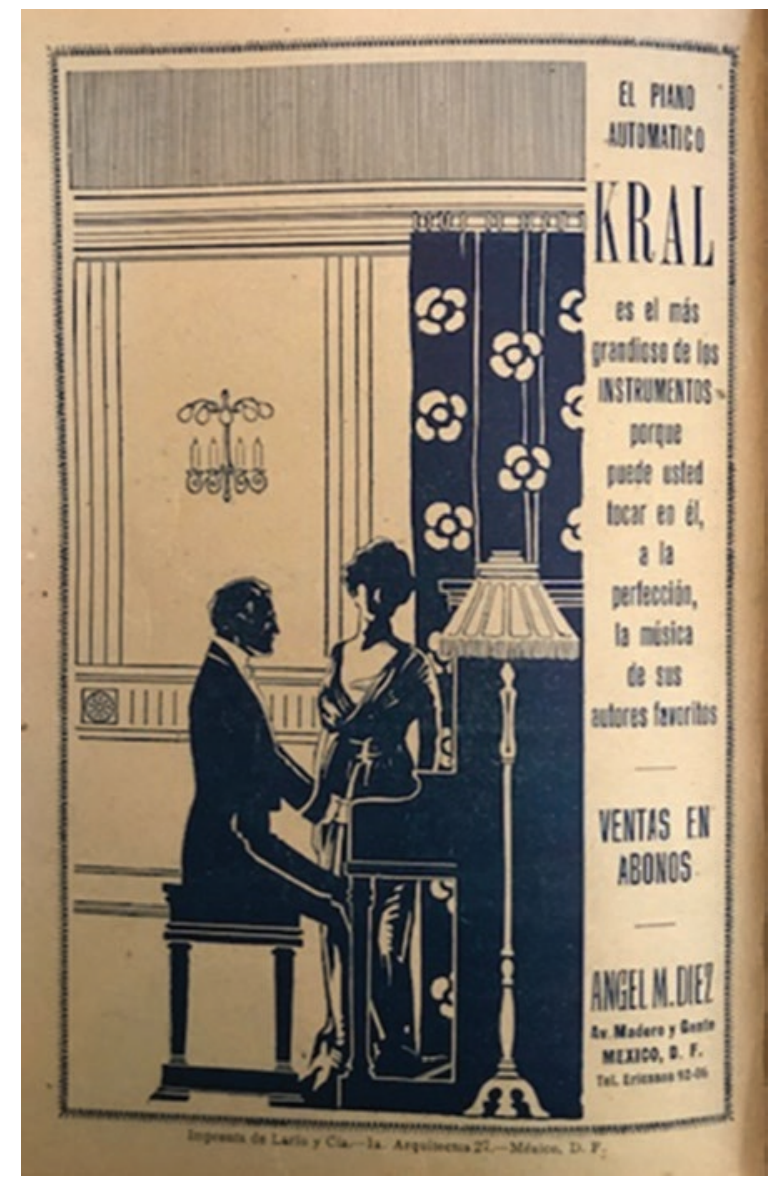

Figura 4. En 1921, Gaceta Médica de México insertó publicidad en sus páginas.

y con fundamentos basados en la experimentación propia o extraña, por lo que se requería de la lectura a través de las revistas médicas. Así, Gaceta Médica, decía Montaño, necesita ser una revista relativamente costosa tanto por su material cuanto por su presentación (Figuras 2 a 4).

\section{Consideraciones finales}

A 100 años de la reanudación de Gaceta Médica de México es pertinente hacer un balance de la publicación como órgano oficial de la Academia Nacional de Medicina. Así como surgió en 1864, por la necesidad de difundir "las ciencias y en especial la medicina", trabajando siempre con "entusiasmo", así continuó la publicación con el cambio de siglo hasta llegar a una interrupción forzosa en 1916. La carestía económica de los azarosos tiempos revolucionarios alcanzó la vida académica, sin embargo, con los esfuerzos de los asociados se logró imprimir de nuevo la publicación que a través de su estructura y contenidos se mostraba como la publicación periódica médica de mayor prestigio. En 1919, al reanudarse Gaceta, se advirtió nuevamente el entusiasmo y compromiso de los autores y editores que recopilaron el material resguardado producto de las continuas sesiones académicas, permitiendo a los lectores retomar el hilo conductor de la asociación: la generación y difusión del conocimiento médico.

\section{Bibliografía}

1. Fernández-Del Castillo F. Algunos datos históricos de la Academia Nacional de Medicina. En: Antología de escritos histórico médicos. México: Universidad Nacional Autónoma de México, Facultad de Medicina; 1978.

2. Jiménez MF. Sesión de clausura del año social 1866. Gac Med Mex. 1866;2:385-386

3. Ruiz LE. Discurso de clausura del año económico 1898 a 1899. Gac Med Mex. 1899;36:526-529.

4. Liceaga E. Algunos datos numéricos sobre la tuberculosis en México. Gac Med Mex. 1899;36:399-405.

5. Mendizábal G. Discurso leído por su autor con motivo de la celebración del $L$ aniversario de la fundación de la Academia Nacional de Medicina. Gac Med Mex. 1915;10:217-233.

6. Cosío JG. Discurso leído por el presidente de la Academia N. de Medicina en la sesión inaugural del día $1^{\circ}$ de octubre de 1915. Gac Med Mex. 1915:1:550-556.

7. Soberón MR. Convocatoria. Gac Med Mex. 1920;1:1-2.

8. Montaño EF. Discurso del presidente saliente. Gac Med Mex. 1920; $1: 561-564$. 